\title{
Fabrication and hemocompatibility assessment of novel polyurethane-based bio-nanofibrous dressing loaded with honey and Carica papaya extract for the management of burn injuries
}

\author{
This article was published in the following Dove Press journal: \\ International Journal of Nanomedicine \\ 2 September 2016 \\ Number of times this article has been viewed
}

\begin{abstract}
Arunpandian Balaji'
Saravana Kumar Jaganathan ${ }^{2-4}$

Ahmad Fauzi Ismail ${ }^{5}$

Rathanasamy Rajasekar 6

'Faculty of Biosciences and Medical Engineering, Universiti Teknologi Malaysia, Johor Bahru, Malaysia; ${ }^{2}$ Department for Management of Science and Technology Development, Ton Duc Thang University, Ho Chi Minh City, Vietnam; ${ }^{3}$ Faculty of Applied Sciences, Ton Duc Thang University, Ho Chi Minh City, Vietnam; ${ }^{4}$ JNUTM Cardiovascular Engineering Centre, Department of Clinical Sciences, Faculty of Biosciences and Medical Engineering, Universiti Teknologi Malaysia, Johor Bahru, Malaysia; ${ }^{5}$ Advanced Membrane Technology Research Center, Universiti

Teknologi Malaysia, Johor Bahru, Malaysia; ${ }^{6}$ Department of Mechanical Engineering, School of Building and Mechanical Sciences, Kongu Engineering College, Tamil Nadu, India
\end{abstract}

Correspondence: Saravana Kumar Jaganathan

Department for Management of Science and Technology Development, Ton Duc Thang University, 19 Nguyen Huu Tho Street, Tan Phong Ward, District 7, Ho Chi Minh City, 70000, Vietnam Email saravana@tdt.edu.vn

\begin{abstract}
Management of burn injury is an onerous clinical task since it requires continuous monitoring and extensive usage of specialized facilities. Despite rapid improvizations and investments in burn management, $>30 \%$ of victims hospitalized each year face severe morbidity and mortality. Excessive loss of body fluids, accumulation of exudate, and the development of septic shock are reported to be the main reasons for morbidity in burn victims. To assist burn wound management, a novel polyurethane (PU)-based bio-nanofibrous dressing loaded with honey (HN) and Carica papaya (PA) fruit extract was fabricated using a one-step electrospinning technique. The developed dressing material had a mean fiber diameter of $190 \pm 19.93 \mathrm{~nm}$ with pore sizes of 4-50 $\mu \mathrm{m}$ to support effective infiltration of nutrients and gas exchange. The successful blending of $\mathrm{HN}$ - and PA-based active biomolecules in PU was inferred through changes in surface chemistry. The blend subsequently increased the wettability (14\%) and surface energy (24\%) of the novel dressing. Ultimately, the presence of hydrophilic biomolecules and high porosity enhanced the water absorption ability of the PU-HN-PA nanofiber samples to $761.67 \%$ from $285.13 \%$ in PU. Furthermore, the ability of the bio-nanofibrous dressing to support specific protein adsorption (45\%), delay thrombus formation, and reduce hemolysis demonstrated its nontoxic and compatible nature with the host tissues. In summary, the excellent physicochemical and hemocompatible properties of the developed PU-HN-PA dressing exhibit its potential in reducing the clinical complications associated with the treatment of burn injuries.
\end{abstract}

Keywords: electrospinning, porous morphology, surface energy, protein adsorption

\section{Introduction}

Among different wound types, burn injuries are difficult to treat because their healing mechanism is more complicated and the formation of scar tissue is inevitable. Pain and the generalized effects on the body experienced by a burn victim are incomparable with other traumas. ${ }^{1-4}$ Initial pathophysiological events associated with burn wound healing include hemostasis and onset of a prolonged inflammatory phase. This leads to the release of several proteins, and formation of edema and exudate at the wound site. Furthermore, the release of histamine and necrosis factors increases the capillary permeability, hydrostatic pressure, and systemic vascular resistance and also reduces the cardiac output to avoid excessive leakage of body fluids. These events are collectively called burn shock; meanwhile, the nutrient-rich exudate may also lead to 
septic shock in response to microbial invasion, thus further exacerbating the systemic healing process. ${ }^{2,4}$

Despite rapid improvements and investments in burn management, an average of 265,000 deaths are reported each year with the vast majority occurring in low- and middle-income countries. ${ }^{5}$ Excessive loss of body fluids, accumulation of exudate, and the development of septic shock are reported to be the main reasons for morbidity in millions of burn victims hospitalized each year. ${ }^{2,3,6}$ To reduce the discomfort and hospital stay of burn victims, researchers are developing advanced dressing materials that are easy to apply, economical, and readily available. An ideal burn dressing should possess better absorption ability to remove copious exudate, maintain a moist environment for rapid reepithelization, breathability, extensive shielding against microbial intrusion, and have the capability to prevent fluid loss. ${ }^{3,4}$ Most of the available products like bandages, gauzes, and films lack the aforementioned prerequisites, which increase the demand for the exploration of better substitutes.

Among several manufacturing methods, nanofiber mats fabricated using the electrospinning technique are reported to satisfy the requirements of an ideal burn dressing. ${ }^{7}$ The native fiber-like morphology makes them highly compatible with body tissues, and it also provides extracellular matrix (ECM)-like structural support for regenerating skin cells. The existence of small interstices and a large surface area to volume ratio enables them to absorb and retain excessive fluid at the wound site to maintain a moist environment. The porous morphology also offers effective infiltration of nutrients, waste materials, and gas exchange required for rapid reepithelialization. ${ }^{8,9}$ In this study, the electrospinning technique was utilized to fabricate a novel polyurethane (PU)-based bio-nanofibrous dressing material loaded with honey (HN) and Carica papaya (PA) extract for treating burn wounds.

To minimize the clinical complications such as fluid loss and onset of septic shock, the burn wound should be protected by an effective dressing. The preferred material also needs to be nontoxic, biocompatible, and able to protect the wound from external mechanical stress. PU is one of the commonly used medical polymers that has been utilized as a dressing material in the form of films, membranes, foams, hydrogels, and so on. Recent studies describing the development of PU-based nanofibrous membranes have demonstrated their excellent ability to establish sustained release of loaded biomolecules for the regeneration of damaged skin cells. ${ }^{10-12}$ The polymer Tecoflex EG-80A selected in this research is a medical-grade thermoplastic polyether-based PU. It is already used in clinical applications for its elastomeric property and good compatibility. Moreover, its slow and steady degradation rate is inferred to match the synthesis of ECM components and tissue regeneration process..$^{13}$

Because of the profound nutritional and medicinal values, $\mathrm{HN}$ has been used as a dressing material for various types of wound. It is a rich source of carbohydrates; on average the sugars make up $82.4 \%$ and the remaining material is composed of water, proteins, amino acids, vitamins, and essential minerals. These biomolecules are proven antimicrobial, anti-inflammatory, antioxidant, and wound-healing agents..$^{14,15} \mathrm{HN}$ is also reported to reduce oedema, ${ }^{14}$ pain, and scar formation, ${ }^{6}$ which are the most important in the management of burn wounds. The topical application of $\mathrm{HN}$ on burn injuries is thought to sterilize the wound site in a shorter time, reduce inflammation, and speed up reepithelization. Meanwhile, it offers extensive shielding against microbial invasion and achieves complete wound closure better than the commercially available silver sulfadiazine dressing. ${ }^{6,14}$ On the other hand, PA fruit extract is also an effective traditional medicine, which is topically applied on wounds to trigger rapid granulation of lost tissue. ${ }^{16,17}$ The biomolecules available in PA fruit are reported to have antimicrobial, antioxidant, and anti-inflammatory properties. ${ }^{17}$ In addition, $\mathrm{HN}$ and PA extracts also recruit fibroblasts and other growth factors, which may ultimately increase the pace of the healing process. ${ }^{18,19}$

The main objective of this study is to determine various physicochemical and blood compatible properties of the fabricated novel PU-HN-PA dressing. Initially, the extracts of $\mathrm{HN}$ and PA were blended with PU and successfully fabricated into a bio-nanofibrous mesh through electrospinning technique. Then, the physicochemical properties such as morphology, porosity, water uptake, thermal stability, surface chemistry, wettability, and energy were comprehensively analyzed. Meanwhile, the in vitro hemocompatibility was also determined by studying protein adsorption behavior, activated partial thromboplastin (APTT), prothrombin time (PT), and hemolysis assay to confirm its compatible nature with host tissue.

\section{Experimental details Materials}

Tecoflex EG-80A medical-grade thermoplastic PU was purchased from LubriZol, Wickliffe, OH, USA. Analytical grade solvents N,N-dimethylformamide (DMF) and chloroform $\left(\mathrm{CHCL}_{3}\right)$ were supplied by Merck Millipore, Darmstadt, Germany. The commercially available Malaysian Tualang 
honey and unripe fruits of PA were purchased locally. The chemical phosphate-buffered saline (PBS, Biotech Grade) was obtained from Biobasic, Markham, Canada, and sodium chloride physiological saline $(0.9 \% \mathrm{w} / \mathrm{v})$ was supplied by Sigma-Aldrich Co., St Louis, MO, USA. The proteins bovine serum albumin (BSA) and human fibrinogen (FB) were purchased from Sigma-Aldrich Co. Furthermore, the reagents used in APTT and PT assay such as rabbit brain activated cephaloplastin, calcium chloride $(0.025 \mathrm{M})$, and thromboplastin (Factor III) were supplied by Diagnostic Enterprises, Solan, India.

\section{Preparation of bio-composite}

Initially, $400 \mathrm{mg}$ of PU beads were dissolved in $10 \mathrm{~mL}$ DMF by magnetic stirring for 24 hours at room temperature to obtain a homogenous solution of concentration $4 \%(\mathrm{w} / \mathrm{v})$. Then, the PA extract was prepared by following the method reported by Nayak et al. ${ }^{20}$ In brief, the collected PA fruit was cleaned with distilled water, and the outer green layer was peeled using a sharp knife and discarded. Then, the inner fleshy part was carefully separated and blended to obtain a homogenous mixture, which was filtered using metallic tea filter before further use. The solutions of $4 \%(\mathrm{w} / \mathrm{v}) \mathrm{HN}$ and $4 \%$ (v/v) PA extract were separately prepared by dissolving in chloroform and DMF, respectively. Finally, the PU-HN-PA bio-composite was prepared by slowly adding $\mathrm{HN}$ and $\mathrm{PA}$ extract solutions to $\mathrm{PU}$ at a ratio of $7: 1.5: 1.5$, respectively, under rigorous stirring for 30 minutes.

\section{Fabrication of PU and bio-nanofibrous dressing}

The electrospinning of PU and bio-composite was performed according to the following procedure. The prepared solution was loaded into a $10-\mathrm{mL}$ plastic syringe attached with an $18-\mathrm{G}$ stainless steel needle and fitted to the syringe pump (SP20, NFiber). The voltage required for electrospinning was supplied using NFiber high voltage unit, and the fibers were collected on a static drum collector covered with aluminum foil. After several trials, the PU was successfully electrospun at a flow rate of $0.700 \mathrm{~mL} / \mathrm{h}$ with an applied voltage of $16 \mathrm{kV}$. The addition of $\mathrm{HN}$ and PA extracts reduced the viscosity of the bio-composite solution. Hence, the flow rate and voltage were changed to $0.750 \mathrm{~mL} / \mathrm{h}$ and $20 \mathrm{kV}$, respectively, to obtain a steady stream of the polymer solution. In both the cases, the collector distance was constantly maintained at $15 \mathrm{~cm}$. The deposited nanofibrous mesh was carefully detached from the collector and dried at $60^{\circ} \mathrm{C}$ for 6 hours inside a laboratory oven.

\section{Physicochemical characterization}

\section{Scanning electron microscopy micrographs}

The fiber diameter and the morphology of the electrospun PU and the bio-nanofibrous dressing were studied using a Hitachi Tabletop scanning electron microscopy unit (TM3000). Before imaging, the nanofiber samples were sputter coated with gold, and the micrographs were captured at a magnification of $6,000 \times$. The diameter size distribution in the fabricated membranes was determined using ImageJ (National Institutes of Health, Bethesda, MD, USA) software by measuring at least 30 individual fibers randomly. ${ }^{21}$ Furthermore, a histogram illustrating the diameter distribution was also generated by utilizing OriginPro 8.5 software (OriginLab Corporation, Northampton, MA, USA).

\section{Porosity and pore size distribution}

The porosity percentage was measured using the density bottle method. ${ }^{22}$ The electrospun meshes were cropped into small rectangular samples. Then, the length (1), thickness ( $\mathrm{t}$ ), width $(\mathrm{w})$, and weight $(\mathrm{m})$ of the cropped samples were recorded to calculate its apparent density $\left(\rho_{i}\right)$, by using Equation 1 .

$$
\text { Apparent }=\frac{\text { Weight of the nanofiber membrane }(\mathrm{m})}{\text { Thickness }(\mathrm{t}) \times \text { Area of the sample }(1 \times \mathrm{w})}
$$

The porosity percentage $(\varepsilon)$ was obtained by substituting the calculated apparent density $\left(\rho_{i}\right)$ and the bulk/standard density $\rho_{0}=1.10 \mathrm{~g} / \mathrm{cm}^{3}$ of PU in Equation 2 .

$$
\text { Porosity percentage }(\varepsilon)=\left(1-\frac{\rho}{\rho_{0}}\right) \times 100 \%
$$

Moreover, the mean pore size, porosity distribution, and pores per unit area in both PU and bio-composite dressing were measured using Image J, and a graphical representation of pore size distribution was prepared through OriginPro 8.5 software.

\section{Attenuated total reflectance Fourier transform infrared spectroscopy analysis}

The chemical composition of the fabricated nanofibrous mesh was analyzed using the attenuated total reflectance Fourier transform infrared spectroscopy (ATR-FTIR) unit. For recording, the infrared (IR) spectra of PU and bio-composite, a small piece of corresponding nanofiber membrane was placed on the sensor. Meanwhile, the IR spectra of HN and 
PA extracts were also obtained to confirm their presence in PU-HN-PA dressing. Zinc selenide ( $\mathrm{ZnSe}$ ) was used as an ATR crystal, which was coupled with the NICOLET IS5 spectrometer. The spectra of each sample were recorded over the range of $600-4,000 \mathrm{~cm}^{-1}$ at 32 scans per minute and averaged at the resolution of $4 \mathrm{~cm}^{-1}$. Finally, the FTIR outline of each sample was drawn, baseline corrected and normalized using the Spekwin32 software.

\section{Contact angle measurement}

The wettability of PU and the bio-nanofibrous dressing was calculated using the VCA Optima contact angle measurement unit (AST Products, Inc., Billerica, MA, USA). Initially, the fabricated wound dressings were cut into identical square samples of dimension $1 \times 1 \mathrm{~cm}^{2}$. Then, three different liquids such as distilled water, glycerol (99.5\%), and diiodomethane (99\%) were used for measuring the contact angle using a separate syringe to avoid cross-contamination. After fitting the syringe loaded with the desired liquid, a droplet of size $2 \mu \mathrm{L}$ was formed at the tip, and it was carefully placed on the test membrane. Within 10 seconds of liquid deposition, the static image of the contact angle was recorded using a high-resolution video camera. Furthermore, the degree of the angle formed was analyzed through computer-integrated software. In this study, the reported contact angle is the mean value of the results from at least three separate trails.

\section{Surface energy of fabricated nanofibers}

The surface energy $\left(\gamma_{\mathrm{s}}\right)$ of the fabricated membranes was calculated by adopting the Owens-Wendt method. ${ }^{23,24}$ Basically, the surface energy is the sum of dispersive $\left(\gamma^{\mathrm{d}}\right)$ and nondispersive $\left(\gamma^{\mathrm{p}}\right)$ interaction as represented in Equation 3.

$$
\left(\gamma_{\mathrm{s}}\right)=\left(\gamma^{\mathrm{d}}\right)+\left(\gamma^{\mathrm{p}}\right)
$$

Owens and Wendt extended the Fowkes equation (Equation 4) by including the nondispersive interaction of the surface and liquid used (Equation 5). It was further simplified and Equation 7 was finally used for calculating the surface energy by substituting the contact angle value of each sample obtained using distilled water and diiodomethane, respectively. ${ }^{24-26}$

$$
\begin{gathered}
2 \sqrt{\gamma_{\mathrm{s}}^{\mathrm{d}}} \gamma_{1}^{\mathrm{d}}=\gamma_{1}(1+\cos \theta) \\
2 \sqrt{\gamma_{\mathrm{s}}^{\mathrm{d}}} \gamma_{1}^{\mathrm{d}}+2 \sqrt{\gamma_{\mathrm{s}}^{\mathrm{p}}} \gamma_{1}^{\mathrm{p}}=\gamma_{1}(1+\cos \theta) \\
\sqrt{\gamma_{\mathrm{s}}^{\mathrm{d}}} \gamma_{1}^{\mathrm{d}}+\sqrt{\gamma_{\mathrm{s}}^{\mathrm{p}}} \gamma_{1}^{\mathrm{p}}=\gamma_{1}(1+\cos \theta) \times 0.5
\end{gathered}
$$

Table I Surface energy components of distilled water and diiodomethane

\begin{tabular}{llll}
\hline Liquid & $\begin{array}{l}\text { Dispersive } \\
\text { component } \boldsymbol{\gamma}_{1}^{\mathrm{d}} \\
\left(\mathbf{m} / \mathrm{m}^{2}\right)\end{array}$ & $\begin{array}{l}\text { Polar } \\
\text { component } \boldsymbol{\gamma}_{1}^{\mathrm{p}} \\
\left(\mathbf{m J} / \mathrm{m}^{2}\right)\end{array}$ & $\begin{array}{l}\text { Surface free } \\
\text { energy } \boldsymbol{\gamma}_{\mathbf{s}} \\
\left(\mathbf{m} / \mathbf{m}^{2}\right)\end{array}$ \\
\hline Distilled water & 21.8 & $5 \mathrm{I}$ & 72.8 \\
Diiodomethane & 50.8 & 0 & 50.8 \\
\hline
\end{tabular}

Note: Data from Ren et al. ${ }^{23}$

$$
\sqrt{\gamma_{\mathrm{s}}^{\mathrm{d}}}+\sqrt{\gamma_{\mathrm{s}}^{\mathrm{p}}}\left(\sqrt{\frac{\gamma_{1}^{\mathrm{p}}}{\gamma_{1}^{\mathrm{d}}}}\right)=0.5 \times(1+\cos \theta) \times \frac{\gamma_{1}}{\sqrt{\gamma_{1}^{\mathrm{d}}}}
$$

where $\theta$ is the contact angle of the corresponding liquid on the nanofiber surface, $\left(\gamma_{1}^{\mathrm{d}}\right)\left(\gamma_{1}^{\mathrm{p}}\right),\left(\gamma_{\mathrm{s}}^{\mathrm{d}}\right)$, and $\left(\gamma_{\mathrm{s}}^{\mathrm{p}}\right)$ are the dispersive and nondispersive components of the liquid and surface, respectively, and $\gamma_{1}$ is the surface energy of the liquid. The values of surface energy, dispersive, and nondispersive component of the liquids used for the calculation are given in Table 1. Finally, the surface energy $\left(\gamma_{\mathrm{s}}\right)$ was derived from Equation 8.

$$
\gamma_{\mathrm{s}}=\gamma_{\mathrm{s}}^{\mathrm{d}}+\gamma_{\mathrm{s}}^{\mathrm{p}}
$$

\section{Water uptake and swelling kinetics}

Absorption of exudate is one of the important prerequisites of burn wound dressing material. So, the water uptake ability and swelling kinetics of the fabricated nanofiber membranes were determined through a conventional gravimetric method. ${ }^{27}$ In brief, the dried electrospun mesh was cut into small rectangles of dimension $10 \times 0.5 \mathrm{~mm}$ (length and width) and weighed. Then, it was completely immersed in a glass beaker filled with $10 \mathrm{~mL}$ distilled water. At the predetermined time points $-0.5,1,2,4,6,12,24,48$, and 72 hours - the samples were taken and gently wiped to remove excess water present on the surface. The swollen membranes were weighed until a constant value was noticed, and the percentage of water uptake at each time was calculated using Equation 9.

$$
\text { Water uptake }=\frac{m_{s}-m_{d}}{m_{d}} \times 100 \%
$$

where $m_{s}$ is the weight of swollen sample and $m_{d}$ is the weight of dry sample, respectively. Moreover, the swelling kinetic was also mapped using GraphPad Prism 6 software (GraphPad Software, Inc., La Jolla, CA, USA) and analyzed.

\section{Thermogravimetric analysis (TGA)}

The thermal stability of PU and the bio-nanofibrous membrane was studied using the PerkinElmer TGA 4000 unit 
(PerkinElmer, Waltham, MA, USA). The samples of total mass $3 \mathrm{mg}$ were placed in an aluminum pan, and the experiment was carried out under a dry nitrogen atmosphere in the temperature range $30^{\circ} \mathrm{C}-900^{\circ} \mathrm{C}$ at an ascending rate of $10^{\circ} \mathrm{C} / \mathrm{min}$. The remaining weight of the sample was recorded at each temperature point, and the values were exported in an Excel sheet. Then, the TGA curve and the corresponding derivative weight loss curve (DTGA) were drawn using OriginPro 8.5 software.

\section{Hemocompatibility assessment of the dressing material}

Ethical statement and collection of blood samples

This study and all the experimental procedures involved in the collection and handling of blood were in accordance with the Declaration of Helsinki and were approved by the Institutional Ethical Committee at PSNA College of Engineering and Technology, Dindigul, India. For collecting the blood samples, a group of healthy adults were recruited and educated about the risks and benefits of blood donation. Then, the participants were given sufficient time to decide whether they would like to take part in the study or not. Finally, the blood was withdrawn via venipuncture after each participant signed the consent form. The freshly drawn whole blood was anticoagulated with acid-citrate-dextrose (56 mM sodium citrate, $65 \mathrm{mM}$ citric acid, $104 \mathrm{mM}$ dextrose) at a ratio of 9:1 (blood/citrate). Citrated blood was centrifuged at 3,000 rpm for 15 minutes to extract platelet-poor plasma.

\section{Protein adsorption studies}

The protein adsorption behavior of PU and the bio-nanofibrous dressing were determined by measuring the adhesion of BSA and FB through a Bradford assay. The principle process involved is the formation of a complex between the Coomassie blue dye in Bradford reagent and proteins present in the solution. Based on the concentration of protein, the color will change - from red-brown to blue - subsequently, the absorption maximum also shifts from 465 to $595 \mathrm{~nm}$. Initially, the fabricated nanofiber membranes were cut into square samples of dimension $0.5 \mathrm{~cm}^{2}$ and introduced into a 96-well plate. Then they were gently washed with deionized water and stabilized in PBS for 30 minutes at $37^{\circ} \mathrm{C}$. Later, $300 \mu \mathrm{L}$ of prepared BSA and FB protein solution $(150 \mu \mathrm{g} / \mathrm{mL}$ [protein/saline]) was added to each well and incubated for 1 hour at $37^{\circ} \mathrm{C}$. The assay was performed in triplicate, and $50 \mu \mathrm{L}$ of protein solution was taken from each well and added to $1.5 \mathrm{~mL}$ of Bradford reagent in the ratio 1:30. The solution was gently mixed and incubated at room temperature for 15 minutes to facilitate complex formation. Finally, the absorbance of protein/Bradford reagent mixture was measured at
$595 \mathrm{~nm}$, and the amount of protein adsorbed was calculated by comparing with the standard curve. ${ }^{28,29}$

\section{APTT assay}

For biomaterials, the APTT assay is a vital test because it represents the effect of the external agent in initiating clot formation. Among the clotting pathways, APTT measures the occurrence of thrombosis through an intrinsic pathway whose activation is triggered by foreign body contact. Initially, both the PU and the PU-HN-PA dressing were trimmed to square samples of dimension $0.5 \times 0.5 \mathrm{~cm}^{2}$. The assay was performed in triplicate, so three square samples of each type were introduced into 96-well plates and gently washed with deionized water. The samples were stabilized in PBS by incubating at $37^{\circ} \mathrm{C}$ for 30 minutes before starting the assay. Initially, $50 \mu \mathrm{L}$ of the obtained platelet-poor plasma was placed on the sample and incubated for 1 minute at $37^{\circ} \mathrm{C}$. Then, $50 \mu \mathrm{L}$ of rabbit brain cephaloplastin reagent was added and incubated for 3 minutes at $37^{\circ} \mathrm{C}$. Finally, the reaction mixture was activated by adding $50 \mu \mathrm{L}$ of $\mathrm{CaCl}_{2}$ and was gently stirred with a sterile steel needle. The time taken for the formation of the white fibrous clot was noted using a chronometer. ${ }^{30}$

\section{PT assay}

The PT assay illustrates the influence of biomaterial contact in activating the extrinsic pathway, which is usually triggered in response to injury or tissue damage. For PT assay, the fabricated nanofibrous membrane was cut into square samples as described in the "APTT assay" section, and the test was also performed in triplicate. The samples were washed with deionized water and incubated in PBS for 30 minutes at $37^{\circ} \mathrm{C}$. It was further incubated in $50 \mu \mathrm{L}$ of platelet-poor plasma at $37^{\circ} \mathrm{C}$ for 1 minute, then $50 \mu \mathrm{L}$ of $\mathrm{NaCl}$-thromboplastin reagent (Factor III) was added and gently stirred with a sterile steel needle until clot formation. ${ }^{30}$

\section{Hemolysis assay}

To determine the effect of fabricated membranes on red blood cells (RBCs), the hemolysis assay was performed using citrated whole blood. Initially, both PU and bio-nanofibrous samples $\left(1 \times 1 \mathrm{~cm}^{2}\right)$ were equilibrated in physiological saline $(0.9 \% \mathrm{w} / \mathrm{v})$ at $37^{\circ} \mathrm{C}$ for 30 minutes. Then, they were incubated with a mixture of aliquots of citrated blood and diluted saline (4:5) for 1 hour at $37^{\circ} \mathrm{C}$. Subsequently, the whole blood was diluted with distilled water (4:5) to cause complete hemolysis and also with physiological saline solution to make positive and negative controls, respectively. After incubation, the samples were retrieved, and the mixtures were centrifuged at 3,000 rpm for 15 minutes. Then, the clear supernatant was 
carefully pipetted out, and the absorbance of each sample was measured at $542 \mathrm{~nm}$ to record the amount of hemoglobin released, which directly represents $\mathrm{RBC}$ damage. ${ }^{31}$ Finally, the percentage of hemolysis or hemolytic index was calculated using the formula

$$
\text { Hemolysis ratio }(\mathrm{HR})=\frac{\mathrm{TS}-\mathrm{NC}}{\mathrm{PC}-\mathrm{NC}} \times 100
$$

where TS, NC, and PC are measured absorbance values of the test sample, negative control, and positive control at $542 \mathrm{~nm}$, respectively.

\section{Results and discussion}

\section{Morphology and diameter distribution of fabricated membranes}

Figure 1 shows a smooth, bead less, and interconnected fibrous morphology of electrospun PU membrane, whereas

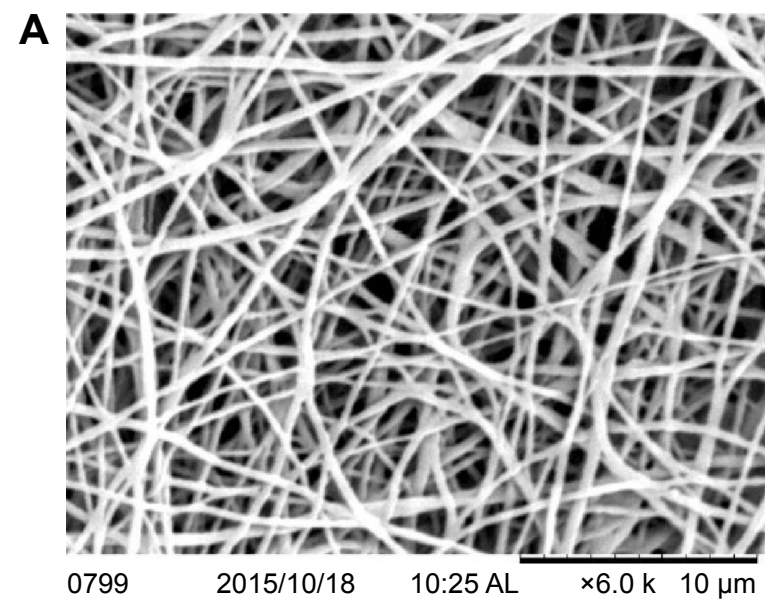

C

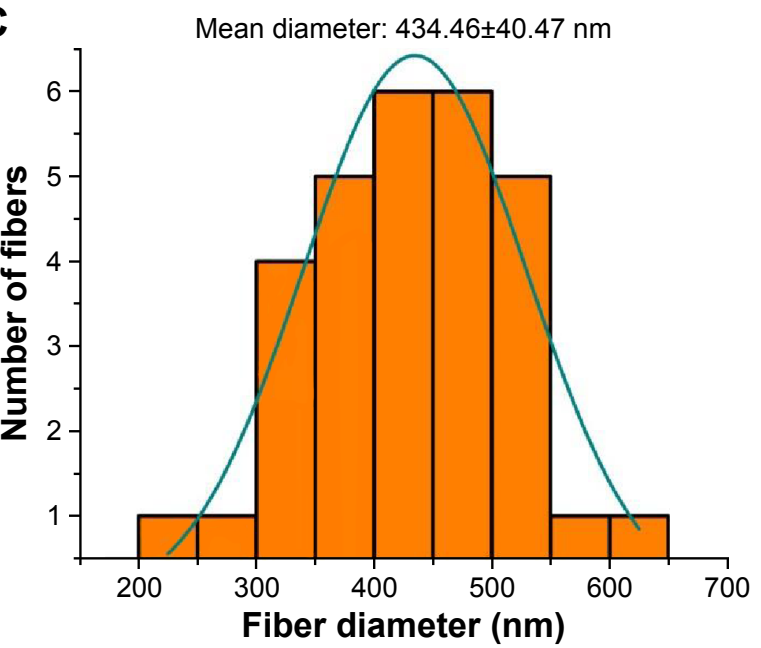

the PU-HN-PA bio-nanofibrous dressing exhibited a slight ribbon-like structure ${ }^{32}$ with uniform fibers and pores. The mean fiber diameters of electrospun PU and PU-HN-PA membranes calculated using ImageJ analysis software were in the range of $434.46 \pm 40.47$ and $190 \pm 19.93 \mathrm{~nm}$, respectively. The diameter of nanofibers was distributed in-between 200-650 nm in PU and 60-260 nm in PU-HN-PA membrane as illustrated in Figure 1. Basically, to achieve complete healing of burn wounds without any impairment, the morphology of dressing material needs to be similar to ECM components because the presence of a native fibrous environment is reported to enhance regeneration activities such as cell adhesion, proliferation, and maturation. ${ }^{7,8}$ From the SEM micrographs, it can be ascertained that the uniform nanofibrous ECM-like morphology of a fabricated dressing may provide better scaffolding to promote timely healing of burn injuries.

The PU membrane is noted to have large pores while in the bio-nanofibrous dressing the pore size is comparatively
B

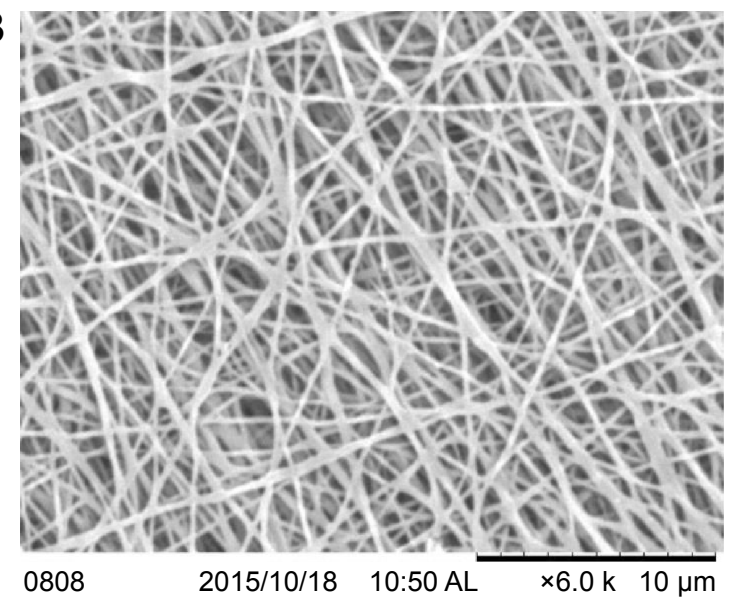

D

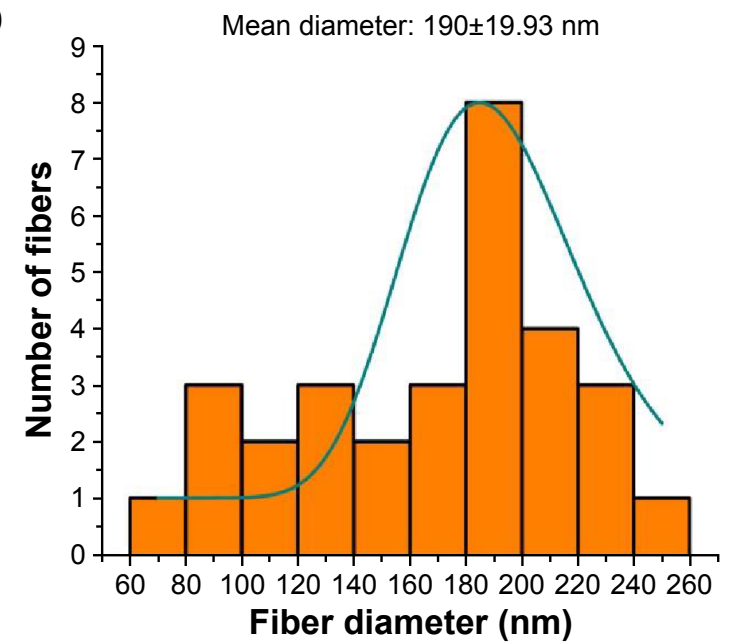

Figure I Nanofiber morphology and diameter distribution of fabricated electrospun membranes.

Notes: Representative SEM images of PU (A) and bio-nanofibrous membrane (B). Diameter distribution histogram of PU (C) and PU-HN-PA (D) dressing materials. Abbreviations: HN, honey; PA, Carica papaya; PU, polyurethane; SEM, scanning electron microscopy. 
low because of the dense fibrous morphology. Similarly, the mean diameter is also reduced by $>50 \%$. This might be due to the changes in conductivity and viscosity of PU solution followed by the addition of $\mathrm{HN}$ and PA extracts. A similar kind of observation is reported by Arslan et al, ${ }^{32}$ when fabricating a PET/honey (HN) nanofibrous scaffold. The percentage of $\mathrm{HN}$ varied at the higher range, the fiber diameter was reduced from $682 \pm 111 \mathrm{~nm}$ to $668 \pm 177 \mathrm{~nm}$ in pristine PET. The observed change was ascribed to enhancement in the electrical properties of PET/HN solution as the conductivity of $\mathrm{HN}$ is $90-130 \times 10^{-5} \mathrm{~S} / \mathrm{cm}$. The impressive electrical conductivity of $\mathrm{HN}$ varies depending on the concentration of biomolecules such as sugars, proteins, minerals, and organic acids. In general, the electrically active solution carries more charges which increase the charge density at the tip of the needle. ${ }^{32}$

Because of this, the pendent droplet might experience strong repulsion and attraction forces from the like charges and the collector, respectively. This may result in greater bending instability and extensive stretching of the electrospun fiber. In a different study, Maleki et al ${ }^{15}$ state that the decrease in viscosity followed by the addition of $\mathrm{HN}$ is also one of the reasons for the change in fiber diameter, along with electrical conductivity. Excitingly, in the present work, the percentage decrease in fiber diameter is significantly higher than the range reported by Arslan et $\mathrm{al}^{32}$ and Maleki et al. ${ }^{15} \mathrm{It}$ suggests that, alongside $\mathrm{HN}$, the addition of PA extract might have affected the electrical conductivity and viscosity of PU solution as PA is also a rich source of several hydrophilic biomolecules. ${ }^{17}$ Figure 2 shows that in PU and PU-HN-PA dressings the nanofibers are steadily distributed between the angles $-90^{\circ}$ to $90^{\circ}$, which confirms the random morphology of the fabricated membrane.

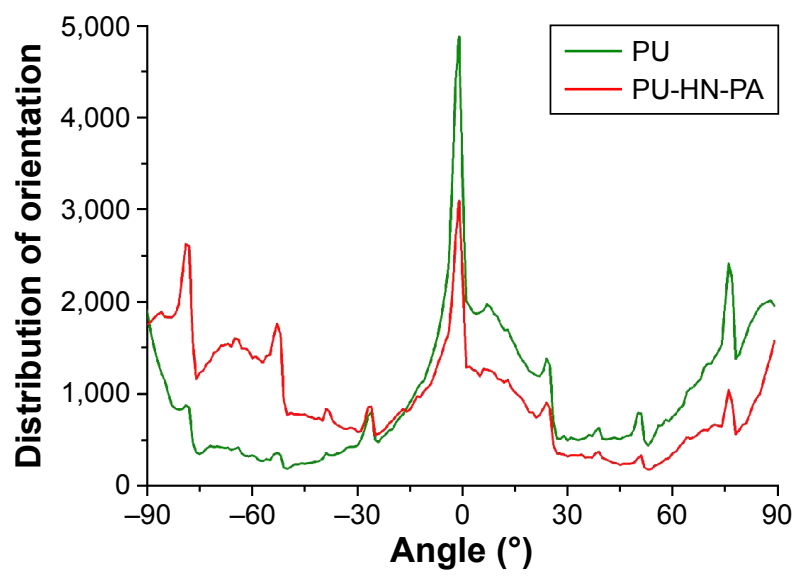

Figure 2 Orientation of fibers in electrospun PU and PU-HN-PA bio-nanofibrous membranes.

Abbreviations: HN, honey; PA, Carica papaya; PU, polyurethane.
Morphology, diameter size, orientation, and interconnectivity of fibers are reported to play a vital role in determining the regeneration ability, ${ }^{33}$ blood compatibility, ${ }^{34}$ and antimicrobial activity of electrospun wound dressing material. ${ }^{35}$ Pelipenko et $\mathrm{al}^{36}$ studied the impact of fiber morphology and diameter size on the proliferation and mobility of fibroblasts and keratinocytes, which are the prime cell types involved in the healing process. They fabricated PVA membranes with different average fiber diameters ranging from 70 to $1,120 \mathrm{~nm}$. The size of keratinocytes was observed to be affected by the fiber diameter; in contrast, the morphology and actin organization of fibroblasts were not influenced much. Ultimately, the thin nanofibers offered better mobility (proliferation and spreading) for both fibroblasts and keratinocytes. The improved proliferation rate was noted on membranes with a mean diameter $>180 \mathrm{~nm} .{ }^{36}$ Similarly, Hsia et $\mathrm{al}^{37}$ also reported that on bioresorbable poly (DTE carbonate) nanofibers, fibroblasts displayed the early development of fibronectin matrices, indicating better proliferation compared to microfibers.

The role of HN and PA fruit extract in recruiting and promoting the proliferation of skin cells is already documented. Arslan et $\mathrm{al}^{32}$ observed changes in the morphology of fibroblast cells cultured on electrospun PET/HN mats during initial days; however, these mats did not influence the proliferation rate and viability. Similarly, Barui et al ${ }^{18}$ also reported spindle morphology of 3T3 fibroblast cells cultured on wet spun alginate/HN fibers. When compared with the control, the HN-loaded fibers exhibited excellent cell viability and maturation and also demonstrated higher expression of collagen I and collagen III molecules. ${ }^{18}$ A comparative study conducted by Tshukudu et $\mathrm{al}^{38}$ revealed the potential of a HN-based scaffold to support the growth of keratinocytes as well. Additionally, the ability of PA fruit extract to recruit fibroblast cells at the wound site and to reduce the inflammation is demonstrated by Nafiu et $\mathrm{al}^{19}$ using animal models.

Like cytocompatibility, the morphology and diameter of the electrospun membrane also influence the blood compatible properties by limiting the interaction with platelets and other blood cells. In a study, Liu et $\mathrm{al}^{34}$ proved that the presence of nanofibrous morphology greatly reduces the adhesion of platelets when compared with microfibers. Basically, the diameter of an individual platelet is approximately 2-4 $\mu \mathrm{m}$, hence on nanofibers the effective area of contact is comparatively low. Once the interaction with platelets is limited, the subsequent host response can be avoided. Therefore, the inferred optimum morphological features 
of fabricated bio-nanofibrous dressings are anticipated to stimulate the healing rate of burn wounds by supporting the regeneration of skin cells and by averting the onset of undesired host reactions.

\section{Percentage porosity and pore size distribution}

Along with fiber morphology, the percentage and size of pores present in a wound dressing material may also influence its healing ability. Porosity is one of the special features available in advanced dressing materials. Several conventional products like gels, ointments, films, and so on used for wound healing achieve an appreciable outcome. However, the complete regeneration/healing of burn wounds is often hindered due to poor gas exchange, waste transport, infiltration to essential nutrients, and cellular interactions. ${ }^{39}$ Advanced medical materials, especially those fabricated through an electrospinning technique, possess a well-ordered and interconnected pore system. Hence, they favor better ventilation and nutrient intrusion, which establishes a suitable environment for adhesion, proliferation, and migration of skin cells.
The percentage porosity measured through the density bottle method indicates that the PU membrane has a mean porosity of $77.78 \%$, whereas in the bio-nanofibrous dressing the porosity is found to be $81.43 \%$ (Figure 3 ). It shows that both PU and PU-HN-PA membranes have high porosity. The $\sim 4 \%$ increase in the porosity of bio-nanofibrous mesh can be attributed to its dense morphology and a high number of fibers, as illustrated in SEM micrographs. In the meantime, the increase in average pore density per $\mathrm{cm}^{2}$ from $56 \times 10^{7}$ in PU to $106 \times 10^{7}$ in bio-nanofibrous composite also supports the effect of dense morphology on measured porosity percentage. The porosity percentage of the fabricated dressing falls in the optimum range required for sustained wound healing. ${ }^{39,40}$

In the PU membrane, the pore size was distributed between 2 and $80 \mu \mathrm{m}$ with a mean value of $15.75 \pm 1 \mu \mathrm{m}$. The bio-nanofibrous mesh exhibited a minor decrease in mean pore size $(12.54 \pm 0.58 \mu \mathrm{m})$, and the distribution fell in the range 4-50 $\mu \mathrm{m}$ as illustrated in Figure 3. In general, the pore size of the dressing material decides the cell type that it can support and the application where it is most effective. This is because each cell type has an optimum pore size in which it can easily infiltrate, migrate, and proliferate. For instance,
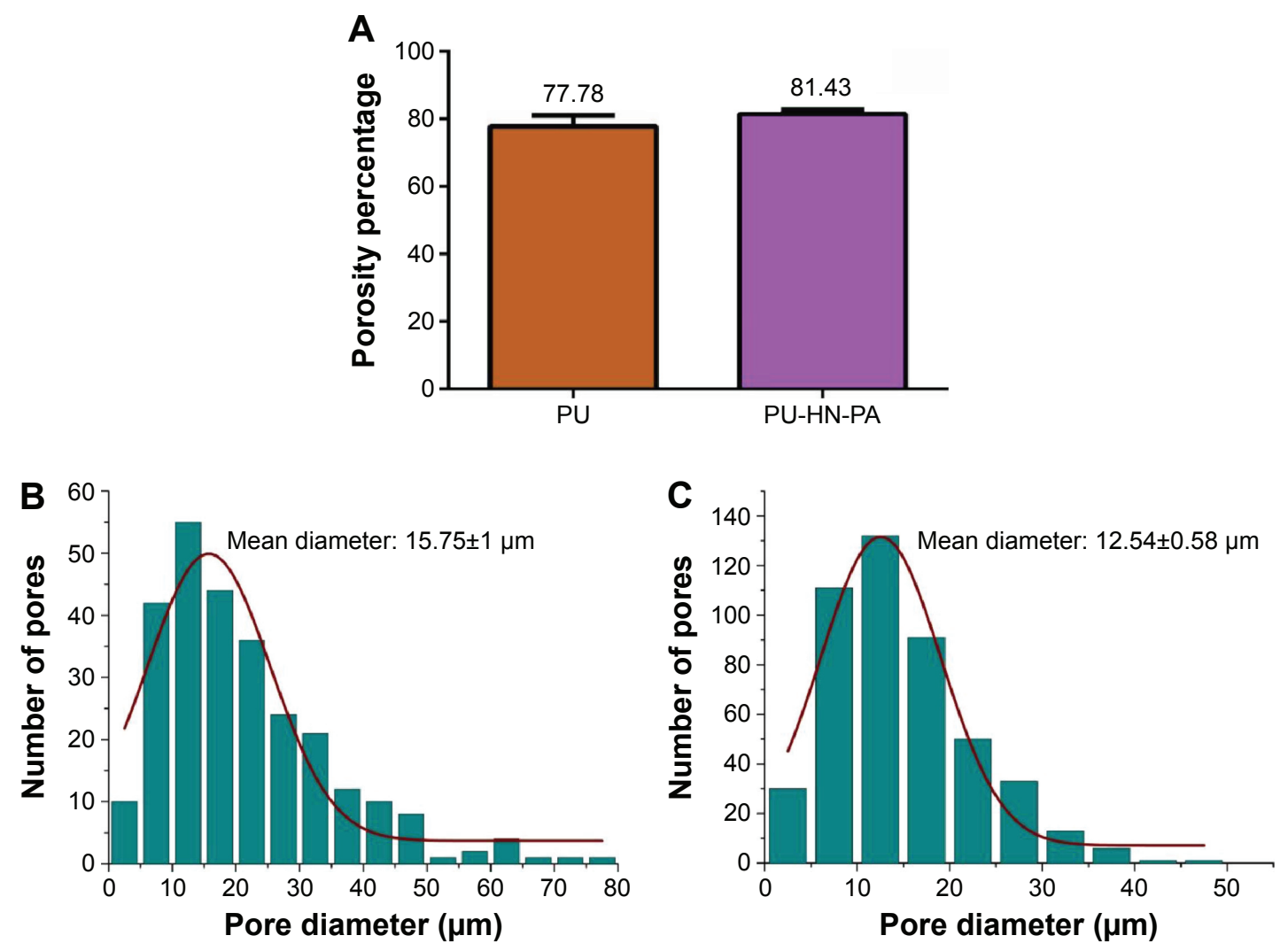

Figure 3 Porosity and pore size distribution of bio-nanofibrous membrane.

Notes: Porosity percentage (A). Pore size distribution of PU (B) and PU-HN-PA (C). Abbreviations: HN, honey; PA, Carica papaya; PU, polyurethane. 
in the case of the fibroblast, pores in the range of 5-15 $\mu \mathrm{m}$ are highly suitable, whereas for bone cells a pore size of $100-350 \mu \mathrm{m}$ is required. ${ }^{41} \mathrm{So}$, the PU-HN-PA membrane is anticipated to act as a plausible dressing for burn wounds since the pore distribution falls in the optimum range of $20-120 \mu \mathrm{m}$ needed for infiltration of skin cells. ${ }^{39}$

\section{Chemical analysis of nanofibrous mesh using FTIR}

The FTIR fingerprint of PU, HN, and PA extract and the bionanofibrous dressing were individually recorded and illustrated in Figure 4. In the PU nanofiber membrane, key peaks were noted at the wavelengths $3,315,2,940,2,853,2,794$,
$1,726,1,698,1,410,1,368,1,220,1,110$, and $1,072 \mathrm{~cm}^{-1}$, respectively. The peak exhibited at 3,315 represents the characteristic N-H stretching of an aliphatic primary amine. The C-H stretching and bending of an alkane in PU can be inferred from the peaks 2,940, 2,853, 2,794, 1,410, and $1,368 \mathrm{~cm}^{-1}$, respectively. ${ }^{42}$ Furthermore, a twin peak noted at 1,726 and $1,698 \mathrm{~cm}^{-1}$ indicates the $\mathrm{C}=\mathrm{O}$ stretching of carboxylic groups while the sharp peaks formed at 1,220, 1,110 , and $1,072 \mathrm{~cm}^{-1}$ specify the C-O stretching corresponding to alcohol groups. Similar observations were reported by Jia et $\mathrm{al}^{42}$ and Kim et al. ${ }^{10}$

A broad peak observed in the FTIR spectra of HN at $3,313 \mathrm{~cm}^{-1}$ depicts $\mathrm{OH}$ stretching of an alcohol group
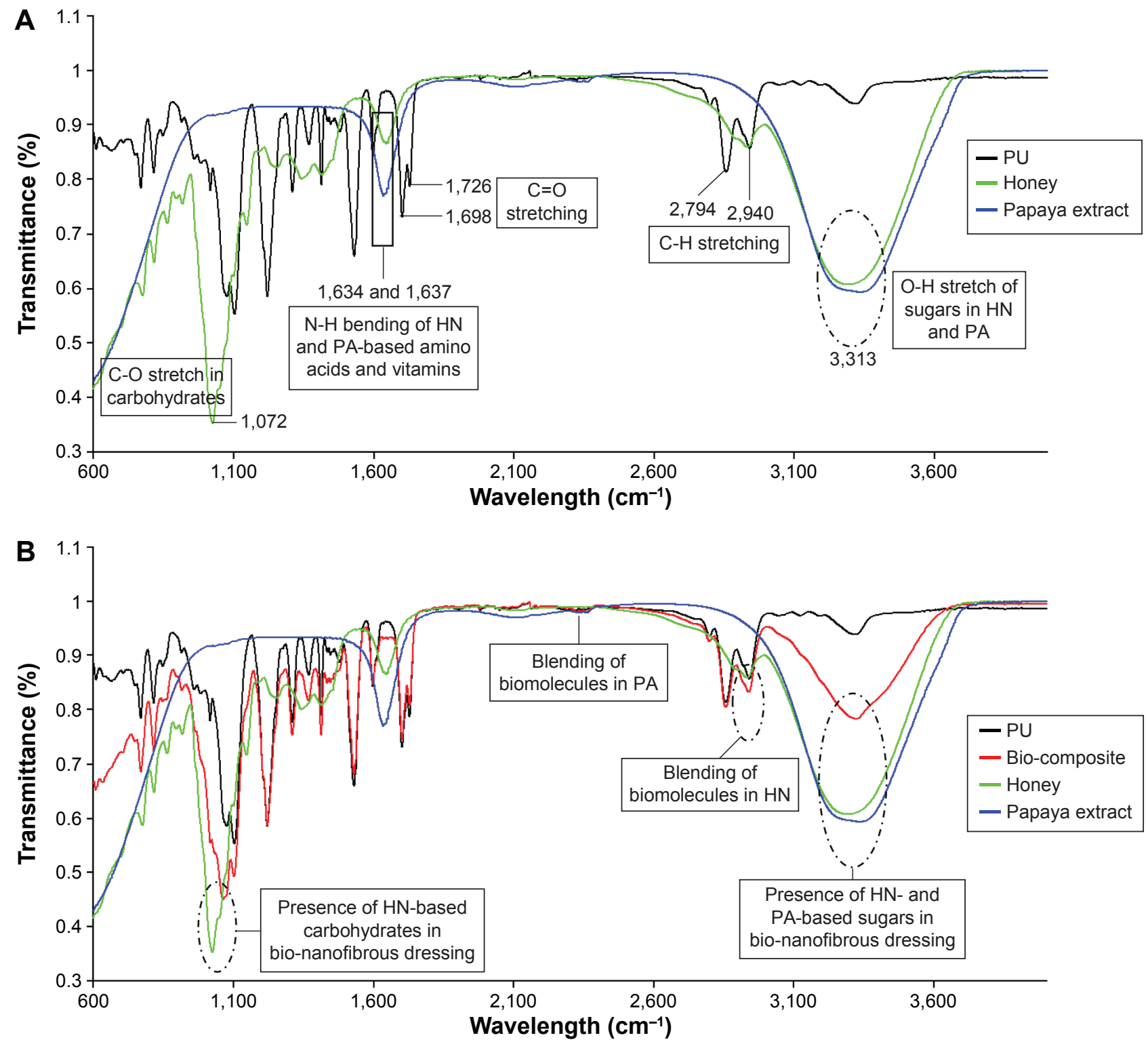

Figure 4 FTIR spectrum of PU, HN, and PA (A) and PU-HN-PA (B) bio-nanofibrous dressing. Abbreviations: FTIR, Fourier transform infrared spectroscopy; HN, honey; PA, Carica papaya; PU, polyurethane. 
present in carbohydrates like fructose, sucrose, glucose, and maltose. The $\mathrm{C}-\mathrm{H}$ stretching and bending of alkanes can be inferred from the peaks at 2,930 and $1,410 \mathrm{~cm}^{-1}$, respectively. Moreover, the N-H bending of amines noted at $1,634 \mathrm{~cm}^{-1}$ may indicate the presence of several vitamins and amino acids. A small peak at $1,338 \mathrm{~cm}^{-1}$ represents the $\mathrm{OH}$ bending of alcohol and phenolic groups, while the peaks at 1,145 and $1,024 \mathrm{~cm}^{-1}$ correspond to the C-O stretching of tertiary and secondary alcohol in sugars. Furthermore, the peak at $1,254 \mathrm{~cm}^{-1}$ demonstrates the $\mathrm{C}$-C stretch in the carbohydrate structure. ${ }^{43-45}$ Similarly, for the PA extract, the functional groups present in various biomolecules like carbohydrates, proteins, vitamins, and so on are illustrated by the peaks formed at 3,315,2,358,2,110, and 1,634 $\mathrm{cm}^{-1}$, respectively. ${ }^{46}$

The blending of $\mathrm{HN}$ and PA extracts with PU resulted in intensity changes and the addition of new peaks in the FTIR spectra of the bio-nanofibrous dressing. Notably, the peak at $3,315 \mathrm{~cm}^{-1}$ broadened and elongated, which may express the addition of an $\mathrm{OH}$ group from sugars present in $\mathrm{HN}$ and PA extracts. The availability of HN-based active biomolecules, such as vitamins and amino acids, in the fabricated PU-HN-PA dressing can be inferred from the increase in the intensity of peaks at $2,940,1,410$, and $1,059 \mathrm{~cm}^{-1}$, respectively. Similarly, the blending of PP extract is indicated by a new peak formed at $2,358 \mathrm{~cm}^{-1}$. In a study, Jia et $\mathrm{al}^{42}$ reported that after blending PU with collagen the FTIR spectra expressed changes in functional groups. In particular, the intensity of the peak specifying N-H stretching of amide A increased with collagen concentration, which symbolized its presence. ${ }^{42}$ Furthermore, Sarhan et $\mathrm{al}^{47}$ demonstrated that the addition of HN to a PVA-chitosan blend led to peak shifts at 3,429 and $1,655 \mathrm{~cm}^{-1}$, representing the availability of new molecules. Therefore, the observed increase in intensity, shifts, and formation of new peaks in FTIR spectra of bionanofibrous membranes exhibit the addition of biomolecules such as sugars, vitamins, and amino acids. As mentioned earlier, the HN and PA extracts are rich sources of antioxidants, anti-inflammatory, antimicrobial, and pain-relieving agents. ${ }^{45}$ Hence, the successful blending confirmed by FTIR analysis indicates the potential of a fabricated PU-HN-PA dressing to locally deliver active molecules required for supporting the healing process and shielding microbial attack at the burn wound site.

\section{Contact angle analysis of the nanofibers}

The wettability indicates several prerequisites of a wound dressing material such as the ability to absorb exudates, maintain a moist environment, and stimulate the cell regeneration rate. ${ }^{10}$ In addition, it also plays a vital role in evading the attacks of the immune system and blood components by encouraging the adsorption of specific plasma proteins. ${ }^{48}$ As mentioned earlier, the anti-thrombogenicity is highly essential for the materials used in burn wound dressing as it frequently encounters body fluids. In this study, the wettability of fabricated membranes was determined using three different liquids. The PU nanofibers showed a mean contact angle of $80.86^{\circ} \pm 1.02^{\circ}$ (for distilled water), and the addition of $\mathrm{HN}$ and PA significantly enhanced the wettability of the bionanofibrous dressing. On average the PU-HN-PA dressing exhibited $\sim 13 \%-14 \%$ increase in hydrophilicity when compared with PU. The contact angle values recorded using three different liquids are summarized in Table 2. The inferred changes in the wettability clearly reflect the advantage of added $\mathrm{OH}$ groups and the active biomolecules from the $\mathrm{HN}$ and PA as illustrated by FTIR spectra. Mary et $\mathrm{al}^{49}$ reported that the wettability of PCL-based nanofibrous composite increased with the concentration of $\mathrm{AV}$ extract $(5 \%, 10 \%$, and $15 \%$ ) mainly due to the presence of aloe-based hydrophilic biomolecules in the test sample. Similarly, Kim et al ${ }^{10}$ also inferred a drastic decrease in the contact angle of PU nanofibers with varying concentrations of gelatin. Moreover, the blending of gelatin also increased the water absorption properties of the composite membrane to a whopping $417 \%$ from only $57 \%$ in PU after 1 hour of immersion.

Basically, to achieve effective regeneration, the scaffold material should allow the deposition of cell adhesive serum proteins such as fibronectin and vitronectin to establish a monolayer to facilitate adhesion, proliferation, and intercellular communication. The long-standing hypothesis about

Table 2 Mean contact angle values and surface energy of PU and PU-HN-PA dressing

\begin{tabular}{|c|c|c|c|c|c|c|}
\hline $\begin{array}{l}\text { Sample } \\
\text { name }\end{array}$ & $\begin{array}{l}\text { Contact angle } \\
\text { using distilled } \\
\text { water }\left({ }^{\circ}\right) \\
\end{array}$ & $\begin{array}{l}\text { Contact } \\
\text { angle using } \\
\text { diiodomethane }\left({ }^{\circ}\right)\end{array}$ & $\begin{array}{l}\text { Contact } \\
\text { angle using } \\
\text { glycerol }\left({ }^{\circ}\right)\end{array}$ & $\begin{array}{l}\text { Dispersive } \\
\text { component } \gamma_{\mathrm{s}}^{\mathrm{d}} \\
\left(\mathrm{mJ} / \mathrm{m}^{2}\right)\end{array}$ & $\begin{array}{l}\text { Polar } \\
\text { component } \gamma_{\mathrm{s}}^{\mathrm{p}} \\
\left(\mathrm{mJ} / \mathrm{m}^{2}\right)\end{array}$ & $\begin{array}{l}\text { Surface free } \\
\text { energy } \gamma_{s} \\
\left(\mathrm{~mJ} / \mathrm{m}^{2}\right)\end{array}$ \\
\hline PU & $80.86 \pm 1.02$ & $51.97 \pm 1.38$ & $90.65 \pm 1.21$ & $33.18 \pm 0.59$ & $4.58 \pm 0.26$ & $37.76 \pm 0.80$ \\
\hline PU-HN-PA & $66.95 \pm 1.14$ & $44.45 \pm 1.93$ & $81.85 \pm 2.00$ & $36.97 \pm 0.80$ & $9.72 \pm 0.46$ & $46.69 \pm 1.01$ \\
\hline
\end{tabular}

Note: Data presented as mean \pm SD.

Abbreviations: HN, honey; PA, Carica papaya; PU, polyurethane. 
the role of wettability in enhancing tissue regeneration is backed by several studies. Faucheux et $\mathrm{al}^{9}$ prepared surfaces with varying wettability in the range of $80^{\circ}-30^{\circ}$ by utilizing self-assembling monolayers of organosilanes. The protein adsorption studies revealed that a surface with moderate wettability $\left(40^{\circ}-70^{\circ}\right)$ is effective in stimulating the deposition of cell adhesive serum proteins. Moreover, the moderate hydrophilic surfaces are also observed to promote the adsorption of ECM components such as collagen, fibronectin, and laminin. ${ }^{50}$ Because of this inherent affinity toward cell adhesive proteins, the moderate hydrophilic surfaces are reported to be suitable for the regeneration of various cell types especially epithelial, fibroblasts, and endothelial cells. ${ }^{50,51}$ In addition, the wettability also plays a vital role in promoting the adsorption of desired plasma proteins and shielding platelet adhesion, which is essential to avoid the undesired host reactions at the wound site. ${ }^{31}$ Hence, the inferred optimum wettability is expected to enhance the water absorption property and hemocompatibility of PU-HN-PA bio-nanofibrous dressing.

\section{Surface energy of fabricated nanofibers}

In addition to wettability, the surface energy of a material also greatly influences its degree of interaction with blood cells and tissues by controlling the adhesion of plasma proteins. In this study, the surface energy was calculated by substituting the contact angle values obtained using distilled water and diiodomethane on fabricated membranes in Owens-Wendt equation. The results indicated a significant difference in the dispersive $\left(\gamma_{\mathrm{s}}^{\mathrm{d}}\right)$ and the polar component $\left(\gamma_{\mathrm{s}}^{\mathrm{p}}\right)$ of the bionanofibrous dressing when compared with PU (Table 2). These changes ultimately increased the surface free energy $\left(\gamma_{\mathrm{s}}\right)$ of PU from $37.76 \pm 0.80 \mathrm{~mJ} / \mathrm{m}^{2}$ to $46.69 \pm 1.01 \mathrm{~mJ} / \mathrm{m}^{2}$ in the fabricated dressing, and it is comparable with the optimum range reported in the literature. ${ }^{52}$ This outcome depicts higher concentration of polar molecules in PU-HN-PA mesh and also validates the results of the FTIR and contact angle assay. The specific protein adsorption is influenced by various physicochemical properties, and the surface energy is one of the important factors. ${ }^{51}$

Whenever a foreign surface comes in contact with body fluids, it will be coated by plasma proteins. However, in materials with high surface energy, the translation of adsorbed protein is reported, which results in the replacement of plasma proteins with cell adhesive fibronectin or vitronectin. In contrast, the materials with low surface energy promote the adsorption of thrombogenic plasma proteins like FB and subsequently accelerate the host reactions. ${ }^{53}$ Because of this, an increase in platelet adhesion, activation of coagulation cascades, and RBCs damage were reported. Moreover, the cell adhesive proteins on materials with high surface energy also induce biofilm formation to enhance the cell adhesion and regeneration process. ${ }^{52}$

\section{Water absorption and swelling kinetics}

Burn wounds are usually sterile at the time of injury, but during the inflammatory phase exudate is formed on the wound surface. Primarily, it is rich in growth factors, dead cells, and wound debris. The purpose of exudate synthesis is to provide a moist environment for triggering reepithelialization and local tissue remodeling. The presence of excessive exudate in burn injuries saturates the wound bed and ultimately causes maceration. Furthermore, it also establishes a healthy platform for microbial ingrowth and creates septic shock which ends up disturbing the healing cycle. Hence, a promising wound dressing material should have the ability to absorb excessive exudate; at the same time it should not dry the wound area. Meanwhile, it also needs to be nonadherent, so that it can be easily removed (if necessary) without causing any damage to the newly developed skin layer. ${ }^{54}$

The electrospun nanofibrous mesh is reported to possess the aforementioned prerequisites, which can be determined through water absorption behavior and swelling kinetics. In this study, the absorption capability of fabricated membranes was studied at different time points from 30 minutes to 72 hours. The PU membrane was found to have a mean absorption percentage of $285.13 \%$, whereas the bio-nanofibrous dressing exhibited an impressive $761.67 \%$ absorption after 72 hours of incubation. When compared with PU, the PU-HN-PA membrane shows an approximately threefold increase in water absorption ability. This significant enhancement can be attributed to the physicochemical changes caused by the blending of $\mathrm{HN}$ and PA fruit extract. The FTIR analysis indicated the availability of several active biomolecules with hydrophilic functional groups. Later, it was confirmed by superior wettability and surface energy. Meanwhile, the enhanced porosity of the bio-nanofibrous membrane may also have contributed to the inferred absorption percentage by supporting the diffusion of more liquid. The addition of hydrophilic substances like gelatin is reported to significantly increase the absorption properties of a $\mathrm{PU}^{10}$ and PLGA nanofibrous scaffold. ${ }^{55}$ Interestingly, the recorded water absorption behavior of PU-HN-PA bio-nanofibrous dressing is highly comparable with the gold standard gelatin-based advanced materials available for burn wound management. ${ }^{10,55}$ 


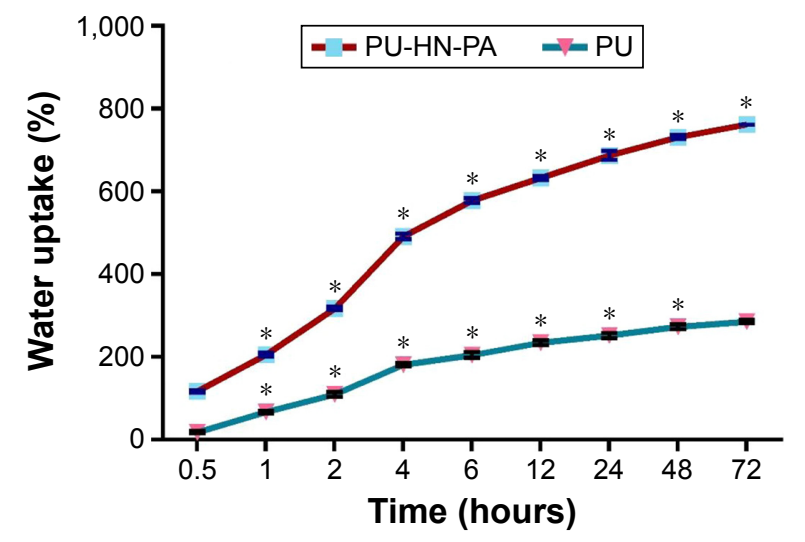

Figure $\mathbf{5}$ Water uptake and swelling kinetics of fabricated nanofibers.

Note: *Indicates the difference in mean value is significant to previous time points. Abbreviations: HN, honey; PA, Carica papaya; PU, polyurethane.

The fabricated mesh also exhibited typical swelling kinetics, that is, a rapid absorption followed by an equilibrium phase as shown in Figure 5. After 1 hour of incubation, both PU and bio-nanofibrous mesh had shown a drastic increase in absorption percentage. As the incubation period increased, the water absorption ability of PU membrane stabilized, and after 48 hours, it did not show any significant change. However, in the bio-nanofibrous mesh, the absorption percentage increased with incubation period, and it also demonstrated significant differences till the maximum time point selected in this study. Hence, from the above observations, it can be deduced that the developed bio-nanofibrous dressing can offer sustained absorption of exudate for a considerable period to avoid the formation of septic shock. Meanwhile, it can also maintain a moist environment required for effective management of burn wounds.
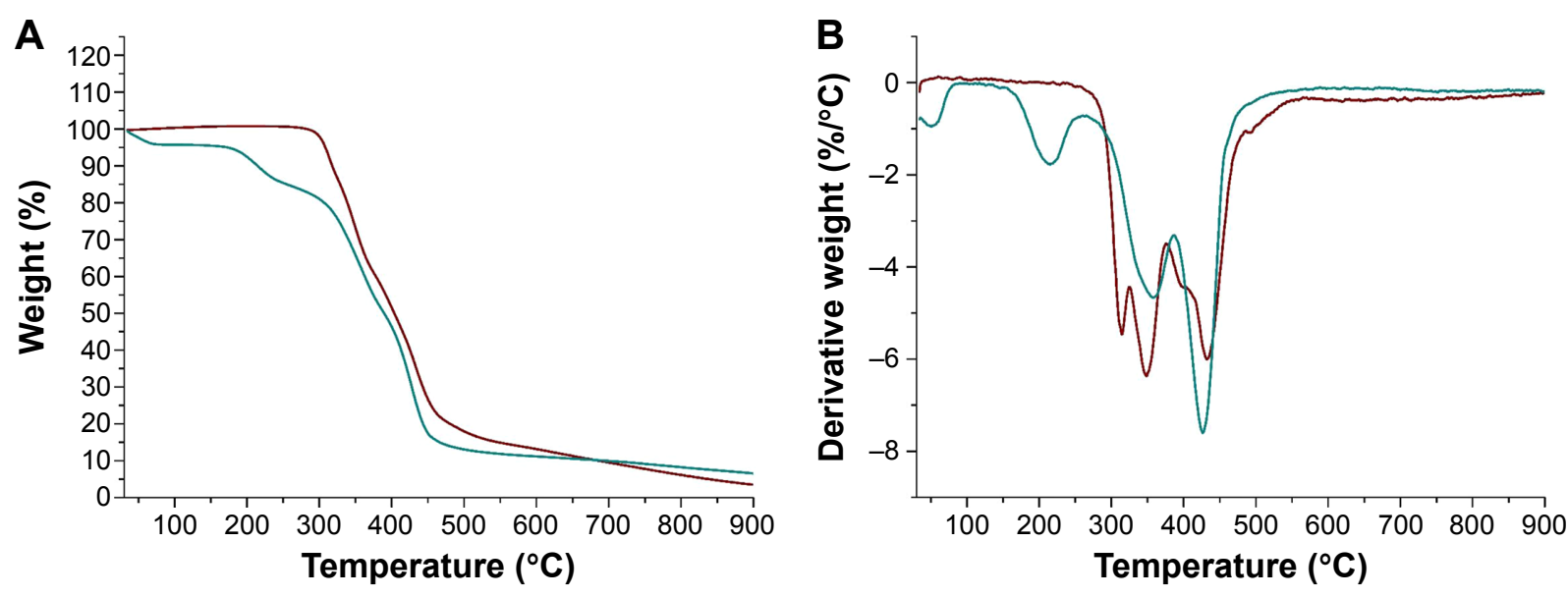

\section{Thermal degradation behavior}

Thermal stability of the fabricated nanofiber dressing was calculated by recording the weight loss in the sample at each temperature between the range $30^{\circ} \mathrm{C}$ and $900^{\circ} \mathrm{C}$. The recorded TGA and DTGA curves are shown in Figure 6, and the weight loss is summarized in Table 3 . From the figures, the decomposition of the polymer at different temperatures can be inferred. In PU, two major and a medium mass loss were noted in the temperature range $250^{\circ} \mathrm{C}-330^{\circ} \mathrm{C}$, $330^{\circ} \mathrm{C}-380^{\circ} \mathrm{C}$, and $380^{\circ} \mathrm{C}-560^{\circ} \mathrm{C}$, respectively. While the bio-nanofibrous membrane exhibited a four-stage weight loss due to the presence of more hydrophilic molecules. It included a negligible loss at $30^{\circ} \mathrm{C}-90^{\circ} \mathrm{C}$ and $165^{\circ} \mathrm{C}-275^{\circ} \mathrm{C}$ followed by a medium and major loss at $273^{\circ} \mathrm{C}-390^{\circ} \mathrm{C}$ and $390^{\circ} \mathrm{C}-500^{\circ} \mathrm{C}$, respectively.

A mass loss of $6 \%$ recorded in PU nanofibers at the temperature range $250^{\circ} \mathrm{C}-330^{\circ} \mathrm{C}$ was due to the evaporation of volatile substances. The first major weight loss of $30 \%$ calculated at $330^{\circ} \mathrm{C}-380^{\circ} \mathrm{C}$ may indicate the decomposition of ester groups related to the hard segment of PU. ${ }^{56}$ Another major loss of $87 \%$ at $380^{\circ} \mathrm{C}-560^{\circ} \mathrm{C}$ can be ascribed to the soft segment decomposition as reported previously. ${ }^{56,57}$ The effect of adding HN and PA extract on the thermal stability of PU can be clearly noted from a slight degradation at the initial temperature $\left(30^{\circ} \mathrm{C}-90^{\circ} \mathrm{C}\right)$ followed by a medium loss of $17 \%$ at $165^{\circ} \mathrm{C}-275^{\circ} \mathrm{C}$. Furthermore, the PU-HN-PA dressing also demonstrated a minor variation in degradation range, and at $500^{\circ} \mathrm{C}$, it lost $\sim 86 \%$ of its total weight. Kim et $\mathrm{al}^{10}$ revealed that the blending of different concentrations of gelatin in PU nanofibers has resulted in additional

\section{$\longrightarrow \mathrm{PU}=\mathrm{PU}-\mathrm{HN}-\mathrm{PA}$}

Figure 6 Thermal stability of PU and PU-HN-PA electrospun membrane.

Notes: (A) TGA graph and (B) DTGA graph.

Abbreviations: DTGA, derivative weight loss curve; HN, honey; PA, Carica papaya; PU, polyurethane; TGA, thermogravimetric analysis. 
Table 3 Selected TGA results of PU and PU-HN-PA dressing

\begin{tabular}{|c|c|c|c|c|c|c|c|}
\hline \multirow{2}{*}{$\begin{array}{l}\text { Name of } \\
\text { the sample }\end{array}$} & \multicolumn{7}{|c|}{ Temperature $\left({ }^{\circ} \mathrm{C}\right)$} \\
\hline & $25 \%$ weight loss & $\mathbf{5 0} \%$ weight loss & $75 \%$ weight loss & Residue (\%) at $900^{\circ} \mathrm{C}$ & $\operatorname{Tmax}_{1}$ & $\operatorname{Tmax}_{2}$ & $\operatorname{Tmax}_{3}$ \\
\hline PU & 346 & 402 & 453 & 3.5 & 320 & 350 & 438 \\
\hline PU-HN-PA & 326 & 387 & 434 & 6.5 & 205 & 354 & 425 \\
\hline
\end{tabular}

Abbreviations: HN, honey; PA, Carica papaya; PU, polyurethane; TGA, thermogravimetric analysis; $T \max _{1}$, temperature at first major weight loss; Tmax ${ }_{2}$, temperature at second major weight loss; $T \max _{3}$, temperature at third major weight loss.

weight loss. Similarly, Agnes et $\mathrm{al}^{49}$ also reported notable alterations in the thermal stability of PCL nanofibers followed by the addition of aloe vera extract. Even though the bio-nanofibrous dressing exhibited premature weight loss, the comparatively increased residual volume at $900^{\circ} \mathrm{C}$ may express its improved thermal stability.

\section{Hemocompatibility of bio-nanofibrous dressing material}

Unlike other traumatic wounds, the dressing materials used for burn healing frequently come in contact with several body fluids, especially in second- and third-grade injuries. As mentioned earlier, the leakage of plasma and other blood components are greater because of the complete erosion of the epidermis and dermis layer. This leaves the victims in the danger of activating an undesired immune response if the material used does not have hemocompatible properties. ${ }^{1}$ The typical host response triggered by the synthetic material includes the formation of thrombosis, inflammation, and foreign body reaction. This will further delay the healing process which usually take years for complete epithelization and maturation. ${ }^{58}$ Hence, in addition to having key characteristics like the removal of copious exudate, infiltration to nutrients, breathability, and scaffolding ability, the dressing should also possess better blood compatible properties.

\section{Adsorption of plasma proteins}

Typically, the interaction of synthetic materials with blood leads to the capping of plasma proteins. If the material lacks hemocompatibility, it promotes the adsorption of unspecific proteins like FB followed by the adhesion and aggregation of platelets. However, if the material possesses blood compatible properties, it will facilitate albumin adsorption to shield the activation of coagulation cascades and also trigger the deposition of cell adhesive proteins. ${ }^{58}$ Hence, an ideal dressing should have better shielding against FB adsorption and also support the adhesion of albumin and other specific plasma proteins.

The amount of albumin and FB adhered on the PU nanofiber membrane was calculated as 27.60 and $29.93 \mu \mathrm{g} / \mathrm{cm}^{2}$, respectively. The bio-nanofibrous dressing demonstrated an impressive $45 \%$ increase in albumin adsorption $\left(43.75 \mu \mathrm{g} / \mathrm{cm}^{2}\right)$ and better shielding against FB $\left(23.10 \mu \mathrm{g} / \mathrm{cm}^{2}\right)$ as shown in Figure 7 . In addition, the increase in $\mathrm{BSA} / \mathrm{FB}$ ratio from 0.925 in pristine $\mathrm{PU}$ to 1.909 in bio-nanofibrous dressing also confirmed the excellent ability of $\mathrm{HN}$ and PA-blended PU to resist the adsorption of nonspecific plasma proteins.
A

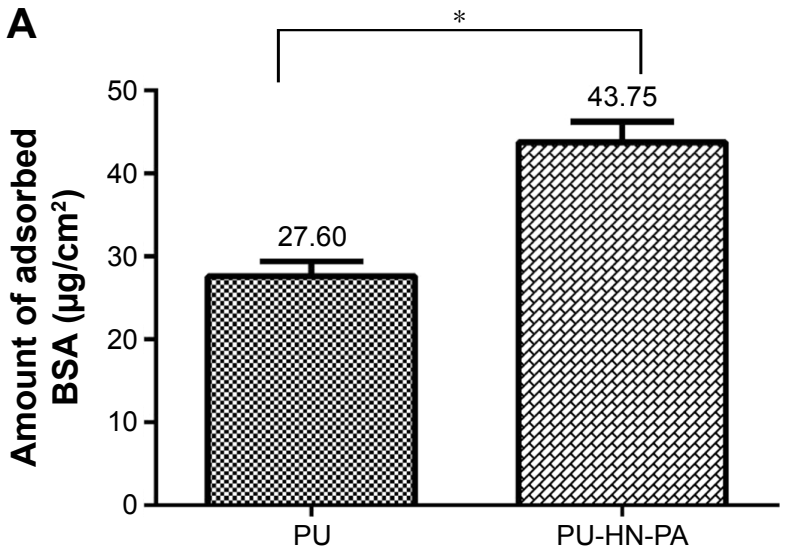

B

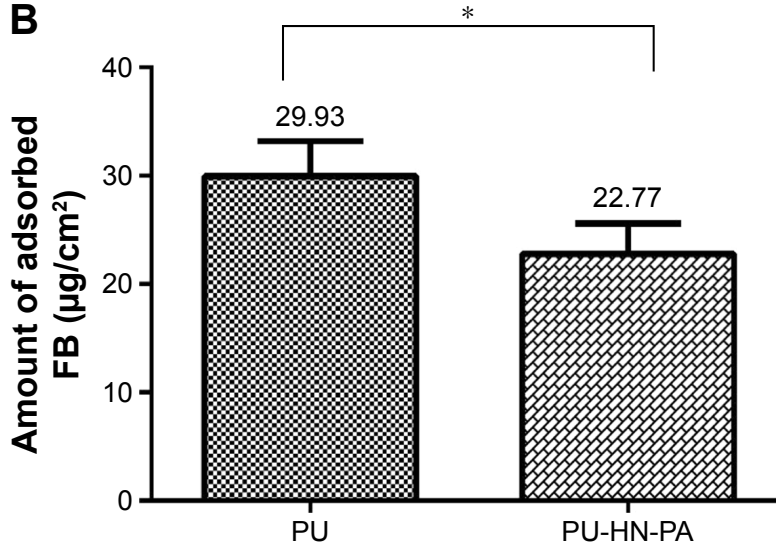

Figure 7 Protein adsorption behavior of $P U$ and bio-nanofibrous dressing $(n=3)$.

Notes: (A) Albumin adsorption and (B) fibrinogen adsorption. *Indicates the difference in mean is significant $(P<0.05)$ with respect to PU.

Abbreviations: BSA, bovine serum albumin; FB, fibrinogen; HN, honey; PA, Carica papaya; PU, polyurethane. 
These improvements can be attributed to changes reported in surface chemistry, wettability, and energy of PU-HN-PA. The inferred specific protein adsorption ability of nanofibrous dressing is anticipated to avoid biomaterial-induced coagulation.

\section{Activation of coagulation cascades}

Building on the results of protein adsorption studies, the influence of fabricated dressing material on the activation of clots through intrinsic and extrinsic pathways was determined using the APTT and PT assays, respectively. The experiments were conducted in triplicate and the calculated mean clotting time is represented in Figure 8. In the APTT assay, the PU nanofiber membrane exhibited a mean clotting time of $152 \pm 1.73$ seconds, whereas in the bio-nanofibrous dressing the thrombosis was delayed and it showed a mean value of $180.3 \pm 1.34$ seconds. Similarly in the PT assay, the clotting time of the bio-nanofibrous dressing was delayed until $45 \pm 0.57$ seconds from the mean clotting time of $37.3 \pm 0.33$ seconds noted in PU. The inferred delay indicated the improved blood compatibility of the bio-nanofibrous membrane when compared with PU. This significant enhancement can be ascribed to its improved physicochemical properties. Meanwhile, the presence of HN- and PA-based biomolecules might also play a vital role in delaying the clotting time.

According to Huang et al, ${ }^{59}$ the blood compatibility of a material is influenced by multiple surface characteristics rather than a single factor. It is backed by several research studies conducted on common medical polymers like PU, PVC, PET, and PP. ${ }^{58}$ The physicochemical characterization experiments depicted commendable changes in surface chemistry, wettability, and energy of the bio-nanofibrous membrane, and it ultimately resulted in better adsorption of

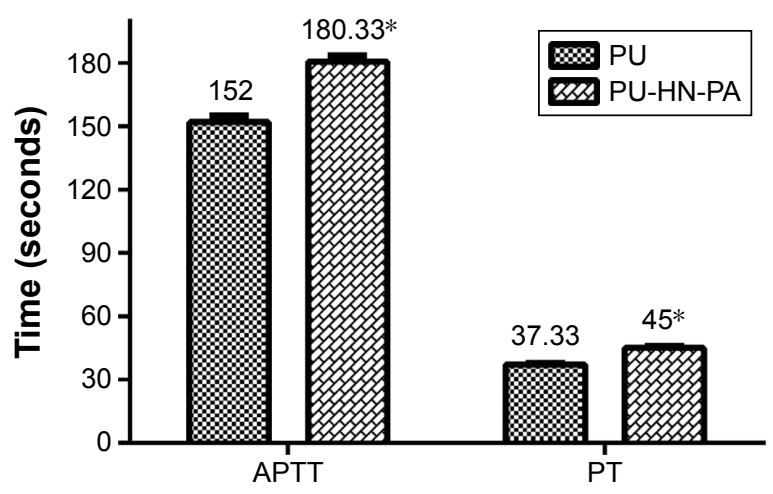

Figure 8 Comparison of APTT and PT of fabricated nanofiber membranes $(n=3)$. Note: *Indicates the difference in mean is significant $(P<0.05)$ with respect to PU. Abbreviations: APTT, activated partial thromboplastin time; HN, honey; PA, Carica papaya; PT, prothrombin time; PU, polyurethane. specific plasma proteins. The role of biological substances in improving the hemocompatibility of synthetic materials is already documented. Chen et al inferred that the addition of curcumin increased the clotting time of a PLA nanofibrous membrane by an average of 12.43 and 2.57 seconds in APTT and PT assays, respectively. Furthermore, the improvement was found to depend on the concentration of curcumin added and the best results were obtained for the maximum concentration chosen. ${ }^{60}$ In a different study, Wang et al ${ }^{61}$ determined that the blending of chitosan and surface immobilization of heparin delayed the clotting time of PLA in APTT and PT assays from the initial values of 17 and 8 seconds up to 33 and 9 seconds, respectively. Similar observations were reported by Shin et $\mathrm{al}^{62}$ in a green tea-based polyphonic constituentblended PLGA nanofibrous membrane. Interestingly, the trend reported in the aforementioned studies showed an average 20-second increase in APTT and 5-second increase in PT after blending the active constituents. But in the present study, the addition of HN and PA extract increased the APTT by approximately 28 seconds and PT by approximately 7 seconds; hence, the blood compatibility of the fabricated bio-nanofibrous membrane is highly comparable with the previously reported combinations.

\section{Determination of hemolytic index}

The hemolysis assay is a simple and important blood compatibility test since it is reported to be an indicator of cytotoxicity of the desired material. In general, when RBCs comes in contact with water, they are subjected to complete lysis by releasing hemoglobin and other biomolecules. However, the rupturing phenomenon is also reported during contact with foreign substances due to excessive osmotic stress exerted from the incompatible material surface. ${ }^{63}$ The adenosine diphosphate released by the damaged RBCs is reported to intensify the attraction and assembly of platelets towards the material surface. This, in turn, may speed up the triggering of coagulation cascades and thrombosis, ${ }^{58,63}$ eventually disturbing the wound healing cycle. Hence, an ideal burn dressing material should not damage the circulating RBCs at the wound site besides not influencing the activation of coagulation pathways.

In this study, the damage caused to the RBCs by PU and the bio-nanofibrous dressing was determined by recording the absorbance of obtained supernatant at $542 \mathrm{~nm}$, which expresses the percentage of hemoglobin release. Interestingly, the absorbance value noted in PU was significantly higher than that of the bio-nanofibrous membrane, indicating extensive lysis of erythrocytes. The hemolytic index of 


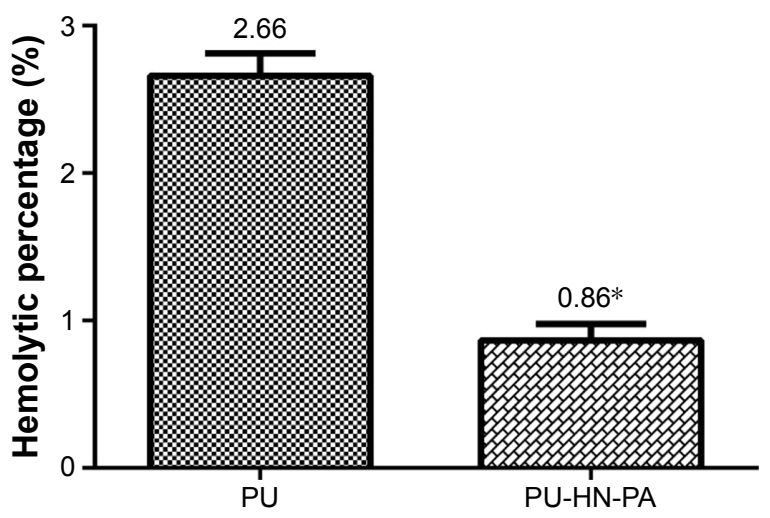

Figure 9 Hemolysis percentage comparison of PU and bio-nanofibrous dressing $(n=3)$.

Note: *Indicates the difference in mean is significant $(P<0.05)$ with respect to PU. Abbreviations: HN, honey; PA, Carica papaya; PU, polyurethane.

PU was found to be $2.66 \%$, whereas for bio-nanofibrous membrane it was only $0.86 \%$ (Figure 9). According to ASTMF756-00 (2000) standard, materials with a hemolysis percentage $>5 \%$ are considered hemolytic, whereas the one between $5 \%$ and $2 \%$ is classified as slightly hemolytic. On the other hand, if the material has a hemolysis percentage $<2 \%$, it is considered to be a nonhemolytic material. ${ }^{64}$ Hence, from the obtained results, the nonhemolytic nature of the fabricated dressing can be realized, which can be ascribed to enhanced physicochemical properties and presence of active biomolecules.

\section{Conclusion}

A novel PU-based bio-nanofibrous dressing loaded with $\mathrm{HN}$ and PA extracts was successfully fabricated through the one-step electrospinning technique. The inferred smooth and interconnected nanofibrous porous morphology may mimic native ECM structure and also support effective infiltration of nutrients. Furthermore, the availability of $\mathrm{HN}$ - and PAbased sugars, proteins, and vitamins ensure local delivery of active biomolecules to assist the regeneration process. Meanwhile, the optimum wettability and surface energy of the PU-HN-PA dressing can trigger the deposition of cell adhesive proteins. Its excellent water absorption properties may avoid the accumulation of exudate at the wound site and also maintain a moist environment for rapid healing. Finally, the excellent ability to avoid nonspecific plasma protein adsorption, thrombus formation, and hemolysis may control the disturbance of the wound healing process caused by undesirable host reactions. In future, the in vitro cytocompatibility, antimicrobial properties, and in vivo efficacy of the developed novel dressing material will be studied to confirm its plausible application in the management of burn injury.

\section{Acknowledgment}

This work was partially supported by a research university grant, Vot numbers Q.J130000.2545.12H80 and Q.J130000.2545.14H59.

\section{Disclosure}

The authors report no conflicts of interest in this work.

\section{References}

1. Tiwari VK. Burn wound: how it differs from other wounds? Indian $J$ Plast Surg. 2012;45:364-373.

2. Rowan MP, Cancio LC, Elster EA. Burn wound healing and treatment; review and advancements. Crit Care. 2015;19:243.

3. Atiyeh BS, Hayek SN, William S. New technologies for burn wound closure and healing - review of the literature. Burns. 2005;31:944-956.

4. Hettiaratchy S. ABC of burns pathophysiology and types of burns. BMJ. 2004;328:1427-1429.

5. World Health Organization. Media centre; Burns; Fact sheet number 365, updated April 2014. Available from: http://www.who.int/mediacentre/factsheets/fs365/en/. Accessed May 9, 2016

6. Gupta SS, Singh O, Bhagel PS, Moses S, Shukla S, Kumar R. Honey dressing versus silver sulfadiazene dressing for wound healing in burn patients; a retrospective study. J Cutan Aesthet Surg. 2011;4:183-187.

7. Hassiba AJ, Zowalaty El, Nasrallah GK, et al. Review of recent research on biomedical applications of electrospun polymer nanofibers for improved wound healing. Nanomedicine (Lond). 2016;11: 715-737.

8. Zhang Y, Lim CT, Ramakrishna S, Huang ZM. Recent development of polymer nanofibers for biomedical and biotechnological applications. J Mater Sci Mater Med. 2005;16:933-946.

9. Peng S, Jin G, Li L, et al. Multi-functional electrospun nanofibres for advances in tissue regeneration, energy conversion \& storage, and water treatment. Chem Soc Rev. 2016;45:1225.

10. Kim SE, Heo DN, Lee JB, et al. Electrospun gelatin/polyurethane blended nanofibers for wound healing. Biomed Mater. 2009;4:044106.

11. Sheikh FA, Barakat NAM, Kanjwal MA, et al. Electrospun antimicrobial polyurethane nanofibers containing silver nanoparticles for biotechnological applications. Macromol Res. 2009;17: 688-696.

12. Sheikha FA, Kanjwal MA, Saran S, Chung WJ, Kim H. Polyurethane nanofibers containing copper nanoparticles as future materials. Appl Surf Sci. 2011;257:3020-3026.

13. Detta N, Errico C, Dinucci D, et al. Novel electrospun polyurethane/ gelatin composite meshes for vascular grafts. J Mater Sci Mater Med. 2010;21:1761-1769.

14. Khan FR, Abadin ZU, Rauf N. Honey: nutritional and medicinal value. Int J Clin Pract. 2007;61:1705-1707.

15. Maleki H, Gharehaghaji AA, Dijkstra PJ. A novel honey-based nanofibrous scaffold for wound dressing application. J Appl Polym Sci. 2013; 127:4086-4092.

16. Murthy MB, Murthy BK, Bhave S. Comparison of safety and efficacy of papaya dressing with hydrogen peroxide solution on wound bed preparation in patients with wound gape. Indian J Pharmacol. 2012;44: 784-787.

17. Sadek KM. Antioxidant and immunostimulant effect of Carica papaya Linn. aqueous extract in acrylamide intoxicated rats. Acta Inform Med. 2012;20:180-185.

18. Barui A, Khare R, Dhara S, Banerjee P, Chatterjee J. Ex vivo biocompatibility of honey-alginate fibrous matrix for $\mathrm{HaCaT}$ and 3T3 with prime molecular expressions. J Mater Sci Mater Med. 2014;25: 2659-2667.

19. Nafiu AB, Rahman MT. Selenium added unripe carica papaya pulp extracts enhance wound repair through TGF- $\beta 1$ and VEGF-a signalling pathway. BMC Complement Altern Med. 2015;15:369. 
20. Nayak BS, Pereira LP, Maharaj D. Wound healing activity of Carica papaya L. in experimentally induced diabetic rats. Indian J Exp Biol. 2007:45:739-743.

21. Chen JP, Chiang Y. Bioactive electrospun silver nanoparticlescontaining polyurethane nanofibers as wound dressings. $J$ Nanosci Nanotechnol. 2010;10:7560-7564.

22. Vaz CM, van Tuijl S, Bouten CVC, Baaijens FPT. Design of scaffolds for blood vessel tissue engineering using a multi-layering electrospinning technique. Acta Biomater. 2005;1:575-582.

23. Ren Z, Chen G, Wei Z, Sang L, Qi M. Hemocompatibility evaluation of polyurethane film with surface-grafted poly(ethylene glycol) and carboxymethyl-chitosan. J Appl Polym Sci. 2013;127:308-315.

24. Kozbial A, Li Z, Conaway C, et al. Study on the surface energy of graphene by contact angle measurements. Langmuir. 2014;30:8598-8606.

25. Zenkiewicz M. Methods for the calculation of surface free energy of solids. J Achieve Mater Manuf Eng. 2007;24:137-145.

26. Fernández V, Khayet M. Evaluation of the surface free energy of plant surfaces: toward standardizing the procedure. Front Plant Sci. 2015; $6: 1-11$.

27. Sarkar SD, Farrugia BL, Dargaville TR, Dhara S. Physico-chemical/ biological properties of tripolyphosphate cross-linked chitosan based nanofibers. Mater Sci Eng C. 2013;33:1446-1454.

28. Lu X, Li D, Yan H, Yiyun Z. Application of a modified Coomassie brilliant blue protein assay in the study of protein adsorption on carbon thin films. Surf Coat Tech. 2007;201:6843-6846.

29. Nwokem NC, Nwokem CO, Ella EE, Osunlaja AA, Usman YO, Ocholi OJ. Adsorption of protein on titanium dioxide and titanium dioxide coated surface. J Microbiol Biotech Res. 2012;2:836-840.

30. Yuan W, Feng Y, Wang H, et al. Hemocompatible surface of electrospun nanofibrous scaffolds by ATRP modification. Mater Sci Eng C. 2013; 33:3644-3651.

31. Balaji A, Jaganathan SK, Supriyanto E, Muhamad II, Zahran MK. Microwave assisted fibrous decoration of $\mathrm{mPE}$ surface utilizing aloe vera extract for tissue engineering applications. Int $J$ Nanomedicine. 2015;10:1-15.

32. Arslan A, Şimşek M, Aldemir SD, Kazaroglu NM, Gumusderelioglu M. Honey-based PET or PET/chitosan fibrous wound dressings: effect of honey on electrospinning process. J Biomater Sci Polym Ed. 2014;25: 999-1012.

33. Abrigo M, McArthur SL, Kingshott P. Electrospun nanofibers as dressings for chronic wound care: advances, challenges, and future prospects. Macromol Biosci. 2014;14:772-792.

34. Liu R, Qin Y, Wang H, Zhao Y, Hu Z, Wang S. The in vivo blood compatibility of bio-inspired small diameter vascular graft: effect of submicron longitudinally aligned topography. BMC Cardiovasc Disord. 2013;13:79.

35. Abrigo M, Kingshott P, McArthur SL. Electrospun polystyrene fiber diameter influencing bacterial attachment, proliferation, and growth. ACS Appl Mater Interfaces. 2015;7:7644-7652.

36. Pelipenko J, Kocbek P, Kristl J. Nanofiber diameter as a critical parameter affecting skin cell response. Eur J Pharm Sci. 2015;66:29-35.

37. Hsia HC, Nair MR, Mintz RC, Corbett SA. The fiber diameter of synthetic bioresorbable extracellular matrix influences human fibroblast morphology and fibronectin matrix assembly. Plast Reconstr Surg. 2011;127:2312-2320.

38. Tshukudu GM, Walt MV, Wessels Q. Comparative in vitro study of honey based and silver based wound preparations on cell viability. Burns. 2010;36:1036-1041.

39. Elsner JJ, Kraitzer A, Grinberg O, Zilberman M. Highly porous drugeluting structures from wound dressings to stents and scaffolds for tissue regeneration. Biomatter. 2012;2:239-270.

40. Sheikh FA. Electrospun antimicrobial polyurethane nanofibers containing silver nanoparticles for biotechnological applications. Macromol Res. 2009; 17:688-696.

41. Yang S, Leong KF, Du Z, Chu CK. The design of scaffolds for use in tissue engineering. Part I. Traditional factors. Tissue Eng. 2001;7: 679-689.
42. Jia Li, Prabhakaran MP, Qin X, Ramakrishna S. Guiding the orientation of smooth muscle cells on random and aligned polyurethane/collagen nanofibers. J Biomater Appl. 2014;29:364-377.

43. Subari N, Saleh JM, Shakaff AY, Zakaria A. A hybrid sensing approach for pure and adulterated honey classification. Sensors. 2012;12: 14022-14040

44. Anjos O, Campos MG, Ruiz PC, Antunes P. Application of FTIR-ATR spectroscopy to the quantification of sugar in honey. Food Chem. 2015; 169:218-223.

45. Ahmed S, Othman NH. Review of the Medicinal effects of Tualang honey and a comparison with Manuka honey. Malays J Med Sci. 2013; 20:6-13.

46. Jaina D, Daima HK, Kachhwaha S, Kotharia SL. Synthesis of plantmediated silver nanoparticles using papaya fruit extract and evaluation of their anti-microbial activities. Dig J Nanomater Bios. 2009;4: 723-727.

47. Sarhan WA, Azzazy H. High concentration honey chitosan electrospun nanofibers; biocompatibility and antibacterial effects. Carbohydr Polym. 2015;122:135-143.

48. Menzies KL, Jones L. The impact of contact angle on the biocompatibility of biomaterials. Optom Vis Sci. 2010;87:387-399.

49. Mary A, Giri S, Dev VR. Electrospun herbal nanofibrous wound dressings for skin tissue engineering. $J$ Text Ind. 2014;106:1-14.

50. Faucheux N, Schweiss R, Lutzow K, Werner C, Groth T. Self assembled monolayers with different terminating groups as model substrates for cell adhesion studies. Biomaterials. 2004;25:2721-2730.

51. Chang HI, Wang Y, editors. Cell responses to surface and architecture of tissue engineering scaffolds. In: Regenerative Medicine and Tissue Engineering - Cells and Biomaterials. Intech Publications; 2011:1-21.

52. Poncin-Epaillard F, Legeay G. Surface engineering of biomaterials with plasma techniques. J Biomater Sci Polymer Edn. 2003;14: $1005-1028$

53. Perrenoud IA, Range EC, Mota RP, Durrant SF, Cruz NC. Evaluation of blood compatibility of plasma deposited heparin-like films and SF6 plasma treated surfaces. Mat Res. 2010;13:95-98.

54. Widgerowa AD, King K, Tocco-Tussardi I, et al. The burn wound exudate - an under-utilized resource. Burns. 2015;41:11-17.

55. Meng ZX, Wang YS, Ma C, Zheng W, Li L, Zheng YF. Electrospinning of PLGA/gelatin randomly-oriented and aligned nanofibers as potential scaffold in tissue engineering. Mater Sci Eng C. 2010;30:1204-1210.

56. Trovati G, Sanches EA, Neto SC, Mascarenhas YP, Chierice GO. Characterization of polyurethane resins by FTIR, TGA, and XRD. J Appl Polym Sci. 2010;115:263-268.

57. Cervantes JM, Moo Espinosa JI, Cauich-Rodriguez JV, et al. TGA/FTIR studies of segmented aliphatic polyurethanes and their nanocomposites prepared with commercial montmorillonites. Polym Degrad Stabil. 2009;94:1666-1677.

58. Balaji A, Jaganathan SK, Vellayappan MV, et al. Prospects of common biomolecules as coating substances for polymeric biomaterials. RSC Adv. 2015;5:69660-69679.

59. Huang N, Yang P, Leng YX, et al. Hemocompatibility of titanium oxide films. Biomaterials. 2003;24:2177-2187.

60. Chen Y, Lin J, Wan Y, Fei Y, Wang H, Gao W. Preparation and blood compatibility of electrospun PLA/curcumin composite membranes. Fiber Polym. 2012;13:1254-1258.

61. Wang T, Ji X, Jin L, et al. Fabrication and characterization of heparingrafted poly-L-lactic acid-chitosan core-shell nanofibers scaffold for vascular gasket. ACS Appl Mater Interfaces. 2013;5:3757-3763.

62. Shin YC, Yang WJ, Lee JH, et al. PLGA nanofiber membranes loaded with epigallocatechin-3-O-gallate are beneficial to prevention of postsurgical adhesions. Int J Nanomed. 2014;9:4067-4078.

63. Yuan W, Feng Y, Wang H, et al. Hemocompatible surface of electrospun nanofibrous scaffolds by ATRP modification. Mater Sci Eng C. 2013;33:3644-3651.

64. Fazley M, Elahi GG, Lu W. Hemocompatibility of surface modified silk fibroin materials; a review. Rev Adv Mater Sci. 2014;38:148-159. 
International Journal of Nanomedicine

Dovepress

\section{Publish your work in this journal}

The International Journal of Nanomedicine is an international, peerreviewed journal focusing on the application of nanotechnology in diagnostics, therapeutics, and drug delivery systems throughout the biomedical field. This journal is indexed on PubMed Central, MedLine, CAS, SciSearch ${ }^{\circledR}$, Current Contents ${ }^{\circledR} /$ Clinical Medicine,
Journal Citation Reports/Science Edition, EMBase, Scopus and the Elsevier Bibliographic databases. The manuscript management system is completely online and includes a very quick and fair peer-review system, which is all easy to use. Visit http://www.dovepress.com/ testimonials.php to read real quotes from published authors.

Submit your manuscript here: http://www.dovepress.com/international-journal-of-nanomedicine-journal 